\title{
Simvastatin exerts anticancer effects in osteosarcoma cell lines via geranylgeranylation and c-Jun activation
}

\author{
SHINWAN KANY ${ }^{1 *}$, MATHIAS WOSCHEK $^{1 *}$, NIELS KNEIP $^{1}$, RAMONA STURM $^{1}$, \\ MIRIAM KALBITZ ${ }^{2}$, MARC HANSCHEN ${ }^{3}$ and BORNA RELJA ${ }^{1}$
}

\begin{abstract}
${ }^{1}$ Department of Trauma, Hand and Reconstructive Surgery, University Hospital Frankfurt, Goethe University, D-60590 Frankfurt am Main; ${ }^{2}$ Department of Orthopedic Trauma, Hand, Plastic and Reconstructive Surgery, University of Ulm, D-89081 Ulm; ${ }^{3}$ Department of Trauma Surgery, Technical University Munich, D-81675 Munich, Germany
\end{abstract}

Received October 10, 2017; Accepted January 26, 2018

DOI: $10.3892 /$ ijo.2018.4288

\begin{abstract}
Osteosarcoma is the leading primary bone cancer in young adults and exhibits high chemoresistance rates. Therefore, characterization of both alternative treatment options and the underlying mechanisms is essential. Simvastatin, a cholesterol-lowering drug, has among its pleiotropic effects anticancer potential. Characterizing this potential and the underlying mechanisms in osteosarcoma is the subject of the present study. Human osteosarcoma cells (SaOS-2 and U2OS) were treated with simvastatin (4-66 $\mu \mathrm{M})$ for 48 or $72 \mathrm{~h}$. The effects of downstream substrate mevalonate (MA) or substrates for isoprenylation farnesyl pyrophosphate (FPP) and geranylgeranyl-pyrophosphate (GGPP) were evaluated using add-back experiments. Tumour growth using MTT assay, apoptosis, cell cycle and signalling cascades involved in simvastatin-induced manipulation were analysed. The results revealed that simvastatin dose-dependently inhibited cell growth. Simvastatin significantly induced apoptosis, increased the $\mathrm{Bax} / \mathrm{Bcl}-2$ ratio, and cleavage of caspase- 3 and PARP protein. Simvastatin impaired cell cycle progression as shown by significantly increased percentages of cells in the G0/G1 phase and lower percentages of cells in the S phase. Gene expression levels of cell cycle-regulating genes (TP53, $C D K N 1 A$ and $C D K 1$ ) were markedly altered. These effects were not completely abolished by FPP, but were reversed by MA and GGPP. JNK and c-Jun phosphorylation was enhanced after simvastatin treatment, while those were abolished when either MA or GGPP were added. In conclusion, simvastatin
\end{abstract}

Correspondence to: Dr Borna Relja, Department of Trauma, Hand and Reconstructive Surgery, University Hospital Frankfurt, Goethe University, D-60590 Frankfurt am Main, Germany

E-mail: info@bornarelja.com

${ }^{*}$ Contributed equally

Key words: statin, cancer, osteosarcoma, JNK, Rho proteins, geranylation, prenylation acts primarily by reducing prenylation to induce apoptosis and reduce osteosarcoma cell growth. Particularly enhanced activation of c-Jun seems to play a pivotal role in osteosarcoma cell death.

\section{Introduction}

Osteosarcoma is the most common form of primary malignant bone tumour (1). The annual incidence estimated at 2-5/100,000 individuals is distributed in two peaks regarding the frequency, emerging around the second and seventh decade of life (2). Typical symptoms are swelling, pain and hyperthermia at the affected locus, while in advanced stages pathological fractures occur (3). Here, predominantly the metaphyses of long bones, especially at the knee joints in distal femur and proximal tibia are affected (4). Currently, modern imaging techniques including computer tomography, magnet resonance and positron emission tomography are used for diagnosis and staging. Invasive biopsy and subsequent histological analyses are used for confirming the diagnosis (5). Approximately 85\% of tumours are classified as 'highly malignant' and predominantly show early hematogenous pulmonary metastases $(1,6)$. Still, 80-90\% are thought to present with occult metastases, which cannot be detected with current technology.

The therapeutic strategy for osteosarcoma consists of neoadjuvant systemic polychemotherapy with e.g. doxorubicin, cisplatin, ifosfamide and methotrexate for 10 weeks before surgical treatment (7). Systemic therapy is maintained for up to 30 weeks after surgery. Thereafter, $\sim 70 \%$ of patients are cured (8). The sensitivity of osteosarcoma for radiation therapy is rather limited; however it still remains a treatment option for palliative care (9). In Europe, the immunomodulator mifamurtide or liposomal muramyl tripeptide phosphatidyl ethanolamine (L-MTP-PE) $\left(\right.$ Mepact $^{\circledR}$ ) is available for the treatment of high-grade, non-metastatic osteosarcoma, while it does not display significant effects in the case that the tumour has already spread $(10,11)$. Nevertheless, systemic cancer therapy is a great burden to the body. Apart from osteosarcoma itself, side effects of chemotherapy such as myelosuppression or kidney failure, which can be induced by e.g. cisplatin/ifosfamide, or cardiac failure caused by anthracyclines e.g. doxorubicin, account for the second most common 
cause of death $(12,13)$. Thus, there is a need for alternative or additive therapeutic strategies, which are less harmful to the body.

Statins are administered for cholesterol lowering and in cardiovascular disease due to inhibition of the HMG-CoA reductase and the mevalonate pathway. However, they have been reported to exert anti-invasive, proapoptotic and antiproliferative properties in numerous in vivo and in vitro studies (14). A recent meta-analysis with 7,813 cases demonstrated that statin therapy after cancer diagnosis reduced the hazard of death by $21 \%$ (15). Another meta-analysis with more than one million patients demonstrated that among post diagnosis, statin users had a significantly higher relapse-free survival (16). In numerous human cancer entities e.g. lung, prostate, colon, breast, liver or renal cancer, lipophilic simvastatin caused therapeutic benefits (14,17-20). An impact on small $\mathrm{G}$ proteins and/or suppressed prenylation of key proteins, which regulate the cell cycle and apoptosis (e.g. Rho kinases) are discussed as possible underlying mechanism of the mode of action of statins $(20,21)$. However, the molecular mechanism of simvastatin on osteosarcoma progression has not yet been clarified.

Given the widespread use of statins and the limited systemic treatment options for osteosarcoma, the aim of this study was to evaluate the osteosarcoma cell growth and apoptosis, and underlying mechanisms, as well as the involved regulation of small $\mathrm{G}$ proteins in optional simvastatin therapy.

\section{Materials and methods}

Cell lines and cell cultures. Human osteosarcoma cell lines SaOS-2 and U2OS were purchased from Cell Line Services (Eppenheim, Germany). Tumour cells were cultured at $37^{\circ} \mathrm{C}$ under $5 \% \mathrm{CO}_{2}$ in RPMI-1640 medium (Seromed, Berlin, Germany) supplemented with $10 \%$ heat-inactivated fetal calf serum (FCS), $100 \mathrm{IU} / \mathrm{ml}$ penicillin and $100 \mu \mathrm{g} / \mathrm{ml}$ streptomycin (Gibco, Karlsruhe, Germany) and $20 \mathrm{mM}$ HEPES buffer (Sigma, Steinheim, Germany). The culture media were changed every 2 or 3 days.

Drug treatment. Simvastatin was obtained from Calbiochem (Darmstadt, Germany) and activated prior to the experiments by alkaline hydrolysis of the lactone moiety according to the manufacturer's protocol. Tumour cells were treated for 48 and $72 \mathrm{~h}$ with simvastatin $(4-66 \mu \mathrm{M})$ or with vehicle (ctrl) with fresh changes of culture medium and simvastatin after $48 \mathrm{~h}$. Additionally, mevalonate $(160 \mu \mathrm{M})$, farnesyl pyrophosphate (FPP, $16 \mu \mathrm{M}$ ) and geranylgeranyl pyrophosphate (GGPP, $16 \mu \mathrm{M}$, all from Sigma) were added to the medium containing simvastatin to address simvastatin's site of action along the mevalonate pathway.

Tumour cell growth. MTT kit I 3-(4,5-dimethylthiazol-2-yl)2,5-diphenyltetrazolium bromide (MTT; Roche Diagnostics, Penzberg, Germany) was used to evaluate MTT-reducing activity of the cellular mitochondria. SaOS-2 and U2OS cells $\left(100 \mu 1,1 \times 10^{4} / \mathrm{ml}\right)$ were seeded onto 96-well tissue culture plates and incubated with simvastatin or vehicle as described above to monitor time- and dose-response. Twenty-four hours before the evaluation of each time-point, MTT $(0.5 \mathrm{mg} / \mathrm{ml})$ was added to each well, and the cells were incubated for $4 \mathrm{~h}$ at $37^{\circ} \mathrm{C}$. Thereafter, cells were lysed in a solubilisation solution containing $10 \%$ sodium dodecyl sulphate (SDS) in $0.01 \mathrm{M}$ hydrogen chloride $(\mathrm{HCl})$ and incubated overnight at $37^{\circ} \mathrm{C}$ in $5 \% \mathrm{CO}_{2}$. The following day, the absorbance of each well was measured with a multimode microplate reader (Infinite M200; Tecan, Crailsheim, Germany) at $550 \mathrm{~nm}$. Each experiment was performed in triplicate. After subtracting the background absorbance, the results were expressed as mean cell number. For better comparability of cell growth, the control group was set to $100 \%$ and other groups were measured in relation to the control.

Cell cycle analysis. SaOS-2 and U2OS cells were grown to $70 \%$ confluency, and then treated with simvastatin or vehicle (ctrl). Cell cycle analyses were carried out after 48 or $72 \mathrm{~h}$. Tumour cells were stained with propidium iodide (PI) using a Cycle Test Plus DNA Reagent kit and then subjected to flow cytometry with a FACScan flow cytometer (both from BD Biosciences, Heidelberg, Germany). From each sample, 10,000 cells were measured. Data acquisition was carried out using CellQuest software and cell cycle distribution calculated using ModFit software (BD Biosciences). The number of gated cells in $\mathrm{G} 1, \mathrm{G} 2 / \mathrm{M}$ or $\mathrm{S}$ phase are presented as a percentage (\%). Each experiment was performed in triplicate.

Assessment of apoptosis. After treatment with simvastatin or vehicle (ctrl), SaOS-2 and U2OS cells were incubated with PI and Annexin V-conjugated fluorescein isothiocyanate (FITC) from an Annexin V-FITC Apoptosis Detection kit 1 (BD Biosciences) according to the manufacturer's instructions. Annexin V-FITC/PI binding was evaluated by flow cytometry with a FACScan flow cytometer (excitation wavelength $488 \mathrm{~nm}$, emission wavelength $530 \mathrm{~nm}$; BD Biosciences). The population of PI-negative/Annexin V-positive cells was related to early apoptosis, and that of PI-positive/Annexin V-positive cells was related to late apoptosis/secondary necrosis.

Ribonucleic acid (RNA) isolation, quantitative reversetranscription-polymerase chain reaction ( $R T-P C R)$. Total RNA was isolated using the RNeasy system (Qiagen, Hilden, Germany) according to the manufacturer's instructions. The quality as well as the amount of the isolated RNA were determined photometrically using the NanoDrop ND-1000 device (NanoDrop Technologies, Wilmington, DE, USA). Afterwards, RNA was used for qRT-PCR. Here, RNA was reversely transcribed using the Affinity Script qPCR-cDNA synthesis kit (Stratagene, La Jolla, CA, USA) following the manufacturer's instructions. To determine the mRNA expression of TP53, Cdk1 (CDC 2), CDKN1A, Bax and Bcl-2, qRT-PCR was carried out on a Stratagene Mx3005p qPCR system (Stratagene) using gene-specific primers for human TP53 (NM 000546, UniGene\#: Hs.437460), human Cdk1 (NM 001786, UniGene\#: Hs.732435), human CDKN1A (NM 000389, UniGene\#: Hs.370771), human Bax (NM 004324, UniGene\#: Hs.624291) and human Bcl-2 (NM 000633, UniGene\#: Hs.150749) purchased from SABiosciences (SuperArray, Frederick, MD, USA). The expression of GAPDH with human GAPDH (NM 002046, UniGene\#: Hs.592355; SABiosciences) was measured as a reference gene. qRT-PCR reaction was setup with $1 \mathrm{X} \mathrm{RT}^{2} \mathrm{SYBR}-\mathrm{Green} / \mathrm{Rox}$ qPCR 
Master Mix (SABiosciences) in a $25 \mu \mathrm{l}$ volume according to the manufacturer's instructions. A two-step amplification protocol consisting of initial denaturation at $95^{\circ} \mathrm{C}$ for $10 \mathrm{~min}$ followed by 40 cycles with a $15-\mathrm{sec}$ denaturation at $95^{\circ} \mathrm{C}$ and a 60 -sec annealing/extension at $60^{\circ} \mathrm{C}$ was chosen. The amount of target mRNA in each sample was normalized to the amount of GAPDH mRNA. The relative mRNA expression of target genes after normalization to GAPDH is shown.

Western blot analysis. Total content of cleaved caspase-3 and cleaved PARP, p-JNK, p-c-Jun and c-Jun in SaOS-2 and U2OS cells was evaluated by western blot analysis using anticleaved caspase-3 (clone Asp175, 5A1E), anti-cleaved PARP (clone Asp214, D64E10), anti-p-JNK (clone Thr183/Tyr185), anti-human p-c-Jun (clone Ser63, 54B3), anti-human Jun (clone 60A8) (Cell Signaling Technologies, Cambridge, UK). Tumour cell lysates (50 $\mu$ g protein) were separated by electrophoresis on $12 \%$ polyacrylamide SDS gels and transferred to nitrocellulose membranes (Amersham-Buchler, Braunschweig, Germany). Determination of $\beta$-actin with anti- $\beta$-actin antibody (clone AC-15; Sigma, Taufkirchen, Germany) served as the loading control. Blots were blocked (10\% non-fat dry milk in $1 \mathrm{mM}$ Tris, $150 \mathrm{mM} \mathrm{NaCl}$, pH 7.4) for $1 \mathrm{~h}$, and then incubated for $1 \mathrm{~h}$ at room temperature (RT) with the primary antibody (diluted according to the manufacturer's instructions in blocking buffer with $0.5 \%$ Tween-20 and $0.5 \%$ bovine serum albumin), and then incubated for another hour with horseradish peroxidase-conjugated secondary antibody (HRP-conjugated goat anti-mouse or goat anti-rabbit IgG; cat. no. 12-349 or cat. no. 12-348; Upstate Biotechnology, Lake Placid, NY, USA) diluted 1:5,000 in blocking buffer with supplements at RT. Proteins were detected with $\mathrm{ECL}^{\mathrm{TM}}$ western blot detection reagents (GE Healthcare, Munich, Germany), visualized, digitized, and the integrated density of individual bands was determined using the software Multianalyst (Bio-Rad Laboratories, Inc., Munich, Germany). By densitometric measurements using the same software the amount of protein expression was normalized to $\beta$-actin.

Statistical analysis. All experiments were performed 3-6 times. Differences between groups were determined by WilcoxonMann-Whitney U-test. A P-value of $<0.05$ was considered significant. Data are expressed as mean \pm standard error of the mean (SEM).

\section{Results}

Dose-response analysis of simvastatin in response to U2OS and SaOS-2 cells. Simvastatin was applied in doses of $0,4,8$, 16,33 and $66 \mu \mathrm{M}$ for 48 or $72 \mathrm{~h}$. Both cell lines U2OS (Fig. 1A) and SaOS-2 (Fig. 1B) responded to low-dose simvastatin of $8 \mu \mathrm{M}$; however, this growth reduction was not significant. Fig. 1 reveals that U2OS (Fig. 1A) and SaOS-2 (Fig. 1B) showed a significant reduction in cell growth following treatment with 16 , 33 or $66 \mu \mathrm{M}$ simvastatin for either 48 or $72 \mathrm{~h}$ when compared to the control cells ( $\mathrm{P}<0.05$ vs. $100 \%$ control) (Fig. 1). Treatment for 48 or $72 \mathrm{~h}$, respectively, evoked similar results with regard to cell growth. Therefore, for the following analyses, a dose of 0,16 or $33 \mu \mathrm{M}$ simvastatin and both incubation periods (48 and $72 \mathrm{~h}$, respectively) were applied.
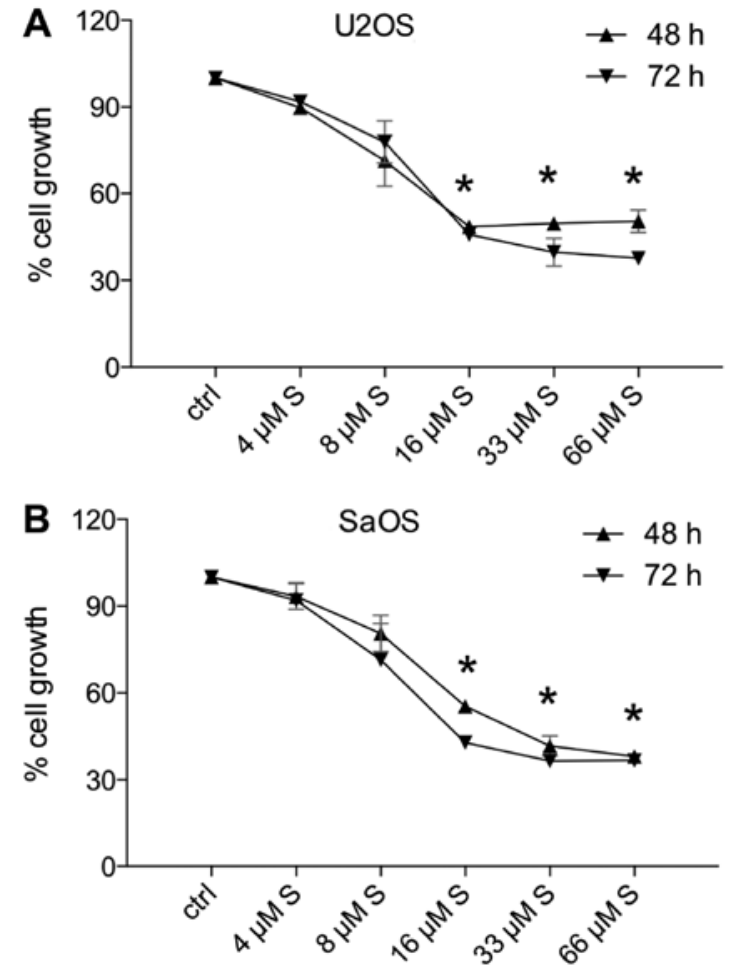

Figure 1. Effects of simvastatin on osteosarcoma cell growth. U2OS (A) and SaOS-2 (B) cells were treated with $0,4,8,16,33$ and $66 \mu \mathrm{M}$ simvastatin (S) or vehicle (ctrl) for 48 or $72 \mathrm{~h}$. Then the 3-(4,5-dimethylthiazol-2-yl)-2,5-diphenyltetrazolium bromide (MTT) dye reduction assay was performed. Data are expressed as mean $\pm \mathrm{SEM} ;{ }^{*} \mathrm{P}<0.05$ in both $\mathrm{S}$ groups vs. ctrl.

Cell growth inhibition potential of simvastatin. Treatment of U2OS (Fig. 2A and B) or SaOS-2 cells (Fig. 2C and D) with either 16 or $33 \mu \mathrm{M}$ simvastatin confirmed the growth-suppressive data, which are shown in Fig. 1. Treatment with doses of 16 or $33 \mu \mathrm{M}$ reduced cell growth of U2OS cells to below $50 \%$, and in SaOS-2 to below 30\% compared to $100 \%$ of controls $(\mathrm{P}<0.05)$ (Fig. 2). After $72 \mathrm{~h}$, viable cells exposed to a high dose of simvastatin reached a growth of $7 \%$ in $\mathrm{U} 2 \mathrm{OS}$ and $10 \%$ in SaOS-2 cells $(\mathrm{P}<0.05)$ (Fig. 2B and $\mathrm{D})$.

Substituting FFP to simvastatin-treated cells showed a trend of increasing cell growth in all experiments. However, the growth of U2OS (Fig. 2A and B) as well as SaOS-2 cells (Fig. 2C and D) was still significantly reduced when compared to the untreated controls $(\mathrm{P}<0.05)$ (Fig. 2).

Addition of GGPP to simvastatin-treated cells resulted in increased cell growth in all experiments, which was not significantly different compared to the untreated controls either after 48 or $72 \mathrm{~h}$, respectively $(\mathrm{P}<0.05)$ (Fig. 2).

Addition of MA to simvastatin-treated cells showed increased cell growth in U2OS cells, which was comparable to the untreated controls (Fig. 2A and B). Treatment of SaOS-2 cells with MA reduced cell growth when compared to the untreated controls (Fig. 2C and D); however this difference was significant only after $48 \mathrm{~h}$ of treatment $(\mathrm{P}<0.05)$ (Fig. 2C).

Nonetheless, the cell growth was consistently increased in all add-back experiments as compared with cells treated with simvastatin alone.

Simvastatin induces cell cycle arrest. To elucidate the underlying mechanism of simvastatin-reduced tumour cell growth, 

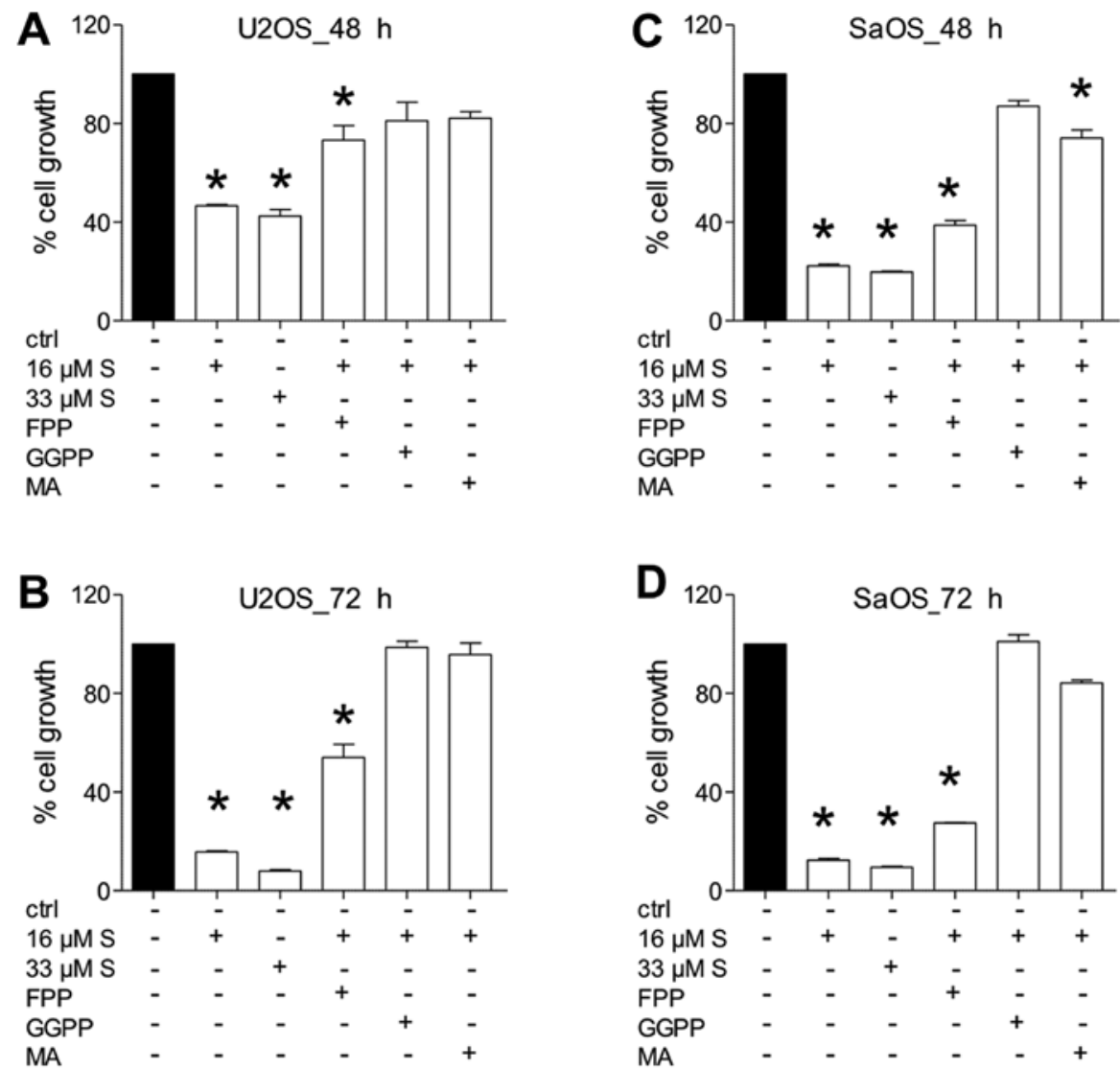

Figure 2. Effects of the mevalonate pathway on osteosarcoma cell growth. U2OS (A and B) und SaOS-2 (C and D) cells were treated with simvastatin (S, 16 or $33 \mu \mathrm{M}$ ) or vehicle (ctrl) for 48 or $72 \mathrm{~h}$, and add-back experiments with farnesyl pyrophosphate (FPP, $16 \mu \mathrm{M})$, geranylgeranyl pyrophosphate (GGPP, $16 \mu \mathrm{M}$ ) and mevalonate (MA, $160 \mu \mathrm{M}$ ) were carried out. Then the 3-(4,5-dimethylthiazol-2-yl)-2,5-diphenyltetrazolium bromide (MTT) dye reduction assay was performed. Data are expressed as mean $\pm \mathrm{SEM} ;{ }^{*} \mathrm{P}<0.05$ vs. ctrl.

the impact of simvastatin on cell cycle distribution was analysed by flow cytometry (Fig. 3A-D). Additionally, the gene expression of relevant cell cycle proteins TP53, CDKN1A and CDC2 (CDK1) (Fig. 3E-G) was examined via qRT-PCR.

Following treatment of U2OS and SaOS-2 cells with simvastatin at each dose, a significant G0/G1 phase arrest was induced compared to the untreated control cells after 48 as well as $72 \mathrm{~h}$, respectively $(\mathrm{P}<0.05)$ (Fig. 3A-D). Simvastatin reduced markedly both, the $S$ phase as well as the G2/M phase concomitant to G0/G1 phase induction (Fig. 3A-D).

Supplementation of FFP to simvastatin-treated cells did not markedly influence the cell cycle distribution as compared to that noted in the simvastatin-treated only cells, and was significant compared to the untreated controls $(\mathrm{P}<0.05)$ (Fig. 3A-D).

However, addition of GGPP or MA to simvastatin-treated cells resulted in a cell cycle distribution, which did not significantly differ from that of the untreated controls (Fig. 3A-D).

To confirm the G0/G1 phase arrest, gene expression of tumour-suppressor protein TP53, which is known to induce cell cycle arrest or apoptosis, the cyclin-dependent kinase inhibitor CDKN1A, which is known to function as a regulator of cell cycle progression at $\mathrm{G1}$, and cyclin-dependent kinase $\mathrm{CDK} 1$, which is responsible for cell cycle progression, were assessed. The gene expression in untreated control cells was set as a reference.

Simvastatin induced a significant increase in TP53 gene expression of up to 20-fold compared to that observed in the untreated control cells $(\mathrm{P}<0.05)$ (Fig. 3E). In cells treated with FFP and simvastatin, TP53 was significantly increased compared to controls and to levels that were observed in the simvastatin-treated only cells $(\mathrm{P}<0.05)$. Substitution with GGPP or MA, respectively, did not induce significant changes in TP53 gene expression compared to the untreated controls (Fig. 3E).

Both doses of simvastatin, 16 and $33 \mu \mathrm{M}$, induced a significant increase in CDKN1A gene expression compared to that noted in the untreated control cells $(\mathrm{P}<0.05)$ (Fig. 3F). Cells treated with either FFP, GGPP or MA and simvastatin did not induce significant changes in CDKN1A gene expression compared to that observed in the untreated controls (Fig. 3F).

Simvastatin significantly decreased CDK1 gene expression compared to that noted in the untreated control cells $(\mathrm{P}<0.05)$ (Fig. 3G). In cells treated with FFP or GGPP and simvastatin, respectively, CDK1 was significantly decreased compared to the controls, and similar to levels that were observed in the simvastatin-treated only cells $(\mathrm{P}<0.05)$ (Fig. 3G). Substitution with MA did not significantly change CDK1 gene expression compared to the untreated controls (Fig. 3G).

Induction of apoptosis in $\mathrm{U} 2 \mathrm{OS}$ and $\mathrm{SaO} 2$ cells by simvastatin. To study the impact of simvastatin on the survival of U2OS and $\mathrm{SaOS}-2$ cells, respectively, flow cytometric analyses, gene expression analyses of pro-apoptotic Bax and anti-apoptotic Bcl-2 as well as western blot analysis for apoptosis inducers 


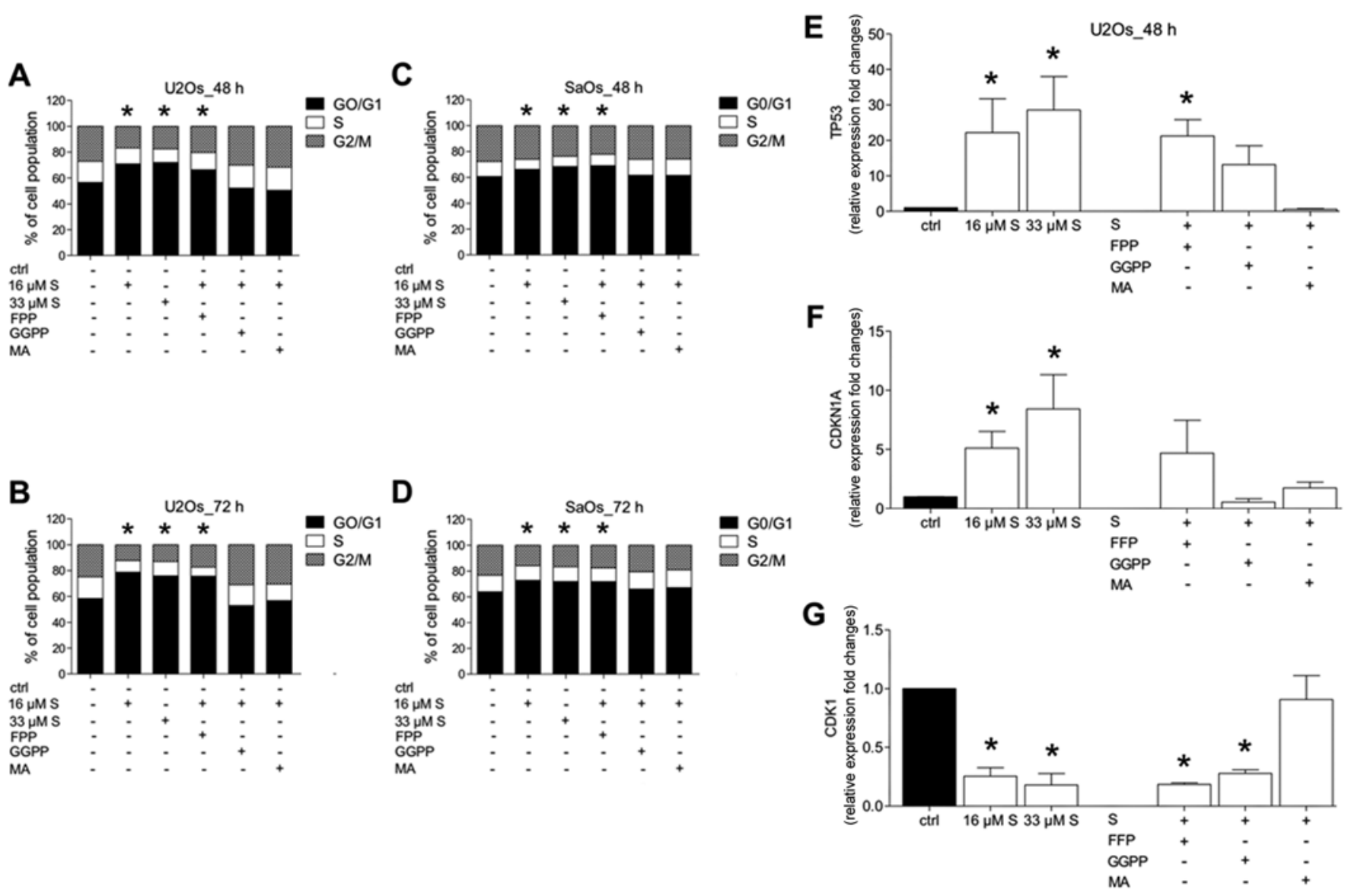

Figure 3. Effects of the mevalonate pathway on the cell cycle of osteosarcoma cells. U2OS (A and B) and SaOS-2 (C and D) cells were treated with simvastatin $(\mathrm{S}, 16$ or $33 \mu \mathrm{M})$ or vehicle (ctrl) for 48 or $72 \mathrm{~h}$, and add-back experiments with farnesyl pyrophosphate (FPP, $16 \mu \mathrm{M})$, geranylgeranyl pyrophosphate (GGPP, $16 \mu \mathrm{M}$ ) and mevalonate (MA, $160 \mu \mathrm{M}$ ) were carried out. Distribution of cell cycle fractions (G0/G1, cell cycle arrest; S, synthesis phase; and G2/M, proliferation or mitosis phase) was determined using propidium iodide staining. Percentages of populations in each cell cycle phase were averaged from three independent experiments (G0/G1 cell cycle arrest, ${ }^{*} \mathrm{P}<0.05$ vs. ctrl). (E-G) U2OS cells were treated as indicated. Gene expression of TP53 (E), CDKN1A (F) and CDK1 $(\mathrm{G})$ after $48 \mathrm{~h}$ was assessed. Data are expressed as mean $\pm \mathrm{SEM} ;{ }^{*} \mathrm{P}<0.05 \mathrm{vs}$. ctrl.

cleaved caspase-3 (cl. caspase-3) or cleaved poly(ADP-ribose)Polymerase (cl. PARP) were performed.

In U2OS and SaOS-2 cells, early and late apoptosis/necrosis were significantly increased by simvastatin treatment (16 and $33 \mu \mathrm{M}$, respectively) at 48 or $72 \mathrm{~h}$, compared to the untreated controls $(\mathrm{P}<0.05)$ (Fig. 4A-D). Similarly, in all experiments, substituting FFP significantly increased apoptosis compared to that noted in the untreated controls $(\mathrm{P}<0.05)$. Treatment with GGPP or MA did not significantly alter the apoptosis rates when compared to the untreated controls (Fig. 4A-D).

The ratio of the gene expression of pro-apoptotic Bax to anti-apoptotic Bcl-2 has been established as a reliable marker for the regulation of cell survival. Examination of the $\mathrm{Bax} / \mathrm{Bcl}-2$ ratio demonstrated $\mathrm{U} 2 \mathrm{OS}$ cells to have a significantly increased Bax/Bcl-2 ratio after their exposure to simvastatin for $48 \mathrm{~h}$ compared to the controls $(\mathrm{P}<0.05)$ (Fig. 4E). This effect was not significantly altered by supplementing FFP, GGPP or MA to simvastatin (Fig. 4E).

Caspase-3 and PARP are crucial to p53-mediated apoptosis. As a zymogen, caspase- 3 becomes activated by its cleavage to cleaved caspase-3, and can in turn process PARP to cleaved PARP. Cleaved PARP cannot fulfill its function on DNA repair and is thus inactive. Both act as surrogate markers for apoptosis. Treating U2OS cells with simvastatin for either
48 or $72 \mathrm{~h}$ induced a strong cleavage of both, caspase- 3 as well as PARP compared to the control (Fig. 4F). Addition of either FFP, GGPP or MA to simvastatin-treated cells reduced the cleavage of caspase-3 and PARP, respectively, and the protein levels were comparable to the untreated controls (Fig. 4F).

Activation of JNK and c-Jun. To further examine the mechanisms of the anticancer mode of action of simvastatin, protein expression levels of activated/phosphorylated JNK (p-JNK) and c-Jun as well as activated/phosphorylated c-Jun (p-c-Jun) were analysed by western blot analysis. Simvastatin treatment at both doses induced a strong increase in the expression of p-JNK and p-c-Jun compared to levels in the untreated control groups (representative figure of U2OS is shown) (Fig. 5). This effect could be partly reversed by addition of FFP, and nearly completely abolished by substitution of either GGPP or MA after 48 as well as 72 h. In Fig. 6. we demonstrate a possible molecular mechanism.

\section{Discussion}

The present study shows that simvastatin, a potent HMG-CoA reductase inhibitor, has the potential to dose- and time-dependently inhibit growth and induce apoptosis in osteosarcoma 

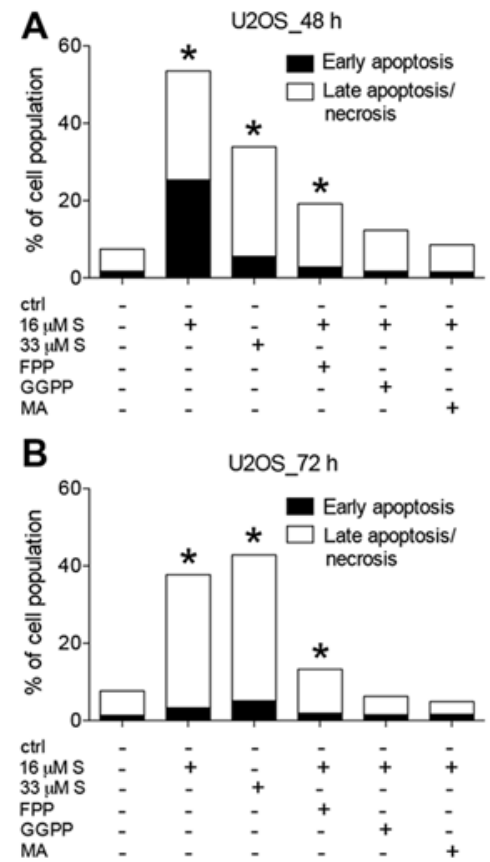

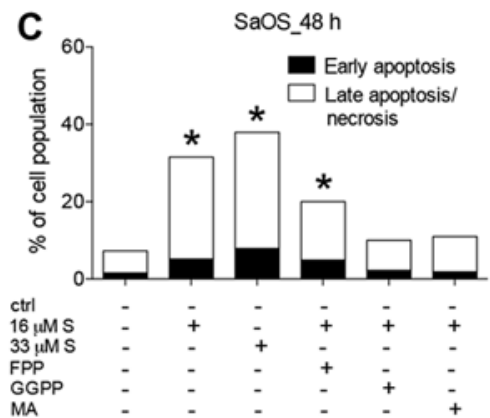

D

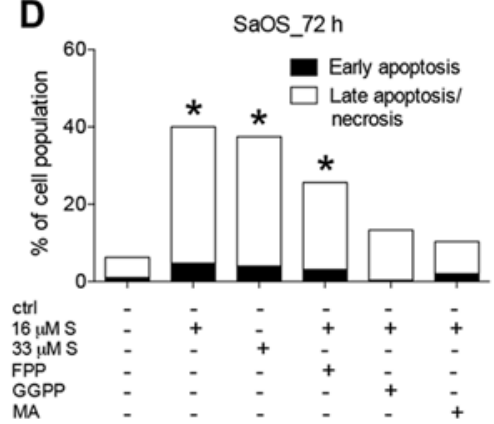

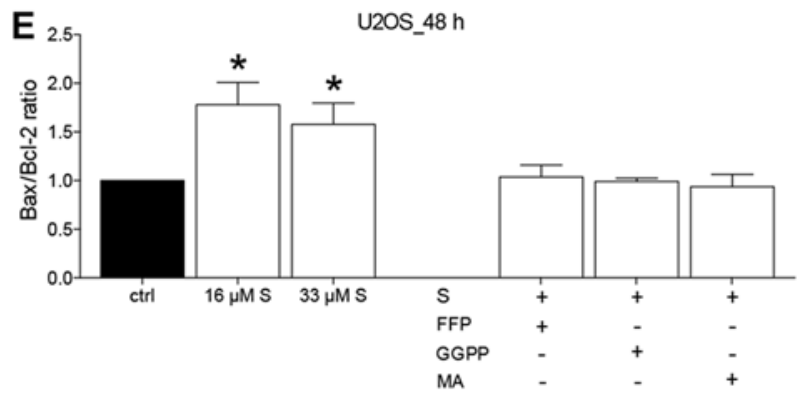

$\mathbf{F}$

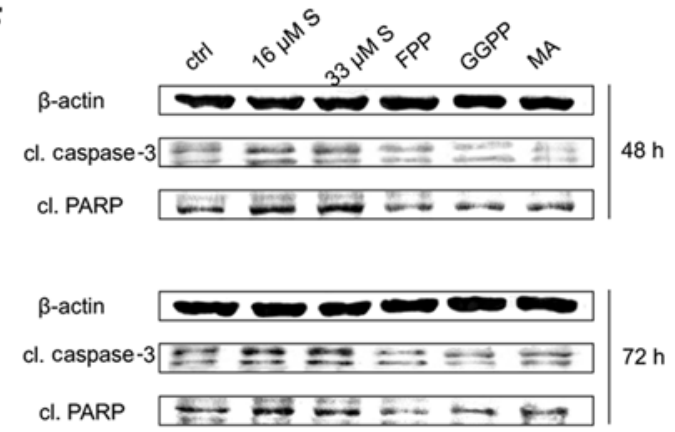

Figure 4. Effects of the mevalonate pathway on osteosarcoma cell apoptosis. U2OS (A and B) and SaOS-2 (C and D) cells were treated with simvastatin (S, 16 or $33 \mu \mathrm{M})$ or vehicle (ctrl) for $48 \mathrm{~h}$, and add-back experiments with farnesyl pyrophosphate (FPP, $16 \mu \mathrm{M})$, geranylgeranyl pyrophosphate (GGPP, $16 \mu \mathrm{M})$ and mevalonate (MA, $160 \mu \mathrm{M}$ ) were carried out. Apoptosis was assessed by staining cells with Annexin V-FITC and propidium iodide (PI). U2OS (A and B) and SaOS-2 (C and D) cells were treated as indicated. PI-negative/Annexin V-positive cells were considered as early apoptotic, and PI-positive/Annexin V-positive cells were considered as late apoptotic/secondary necrotic. The percentage of early apoptotic and late apoptotic/necrotic cells was averaged from all experiments ( ${ }^{*} \mathrm{P}<0.05$ vs. ctrl). U2OS (E and F) cells were treated as indicated. (E) The ratio of the relative Bax and Bcl-2 gene expression was evaluated. (F) Protein levels of cleaved caspase-3 (cl. caspase-3) and cleaved PARP (cl. PARP) were investigated by western blot analysis. $\beta$-actin served as the internal loading control. A representative gel from U2OS cells is shown. Data are expressed as mean $\pm \mathrm{SEM} ;{ }^{*} \mathrm{P}<0.05$ vs. ctrl.

cells. The proposed underlying mechanism of simvastatin's mode of action is via JNK and c-Jun.

Statins, including simvastatin, inhibit $\mathrm{HMG}-\mathrm{CoA}$ reductase via the mevalonate pathway, and are commonly used for cholesterol-lowering in cardiovascular disease $(22,23)$. They exert numerous pleiotropic effects including modulation of inflammation, angiogenesis, neurodegeneration and cancer metastasis, as shown in vitro and in vivo (20). With regard to the mevalonate pathway, the downstream products FPP and GGPP are essential for the prenylation of proteins (24). Many oncogenes from the Ras family, such as Rho A, are partially dependent on post-translational prenylation to be active in cell signaling (24). Cancer cells with their upregulated metabolism imply prenylation of Ras proteins for cell growth, cell cycle and cell signaling. Therefore, inhibiting the mevalonate pathway effectively reduced cancer growth in numerous malignancies including melanoma, glioma, hepatocellular carcinoma and breast cancer among many others $(14,20)$.

The proliferative ability of malignant cells is a major property of sarcoma cells and imperative for cancer assessment (25). The potential of simvastatin to inhibit cell growth of osteosarcoma cells has been controversially discussed. While simvastatin's protective effects for human osteosarcoma cells by reducing oxidative stress and apoptosis have been reported (26), Fromigué et al demonstrated the apoptosis-inducing effects in human osteosarcoma cells as well as suppression of proliferation (27). The latter did, however, not investigate the cell cycle or underlying mechanism addressing the relevant downstream substrates of the mevalonate pathway nor the cell cycle involvement as analysed in the present
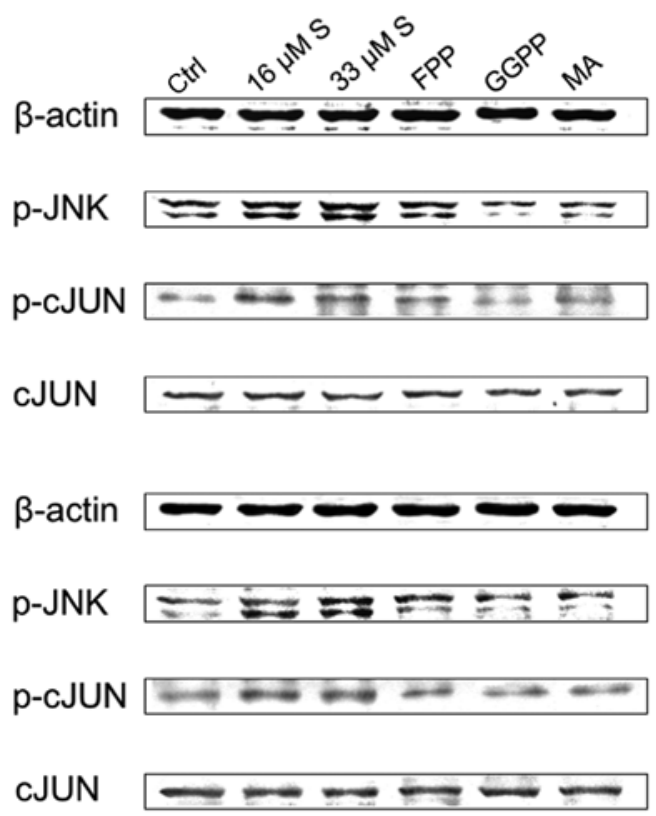

Figure 5. Effects of the mevalonate pathway on osteosarcoma cell signaling. U2OS and cells were treated with simvastatin (S, 16 or $33 \mu \mathrm{M})$ or vehicle (ctrl) for 48 or $72 \mathrm{~h}$, and add-back experiments with farnesyl pyrophosphate (FPP, $16 \mu \mathrm{M}$ ), geranylgeranyl pyrophosphate (GGPP, $16 \mu \mathrm{M}$ ) and mevalonate (MA, $160 \mu \mathrm{M}$ ) were carried out. Analysis of p-JNK, p-c-Jun and c-Jun expression using western blot analysis was performed. $\beta$-actin served as the internal loading control. A representative gel from U2OS cells is shown.

study. Another important disparity between both studies is the applied concentration of simvastatin. While Zhao et al (26) 


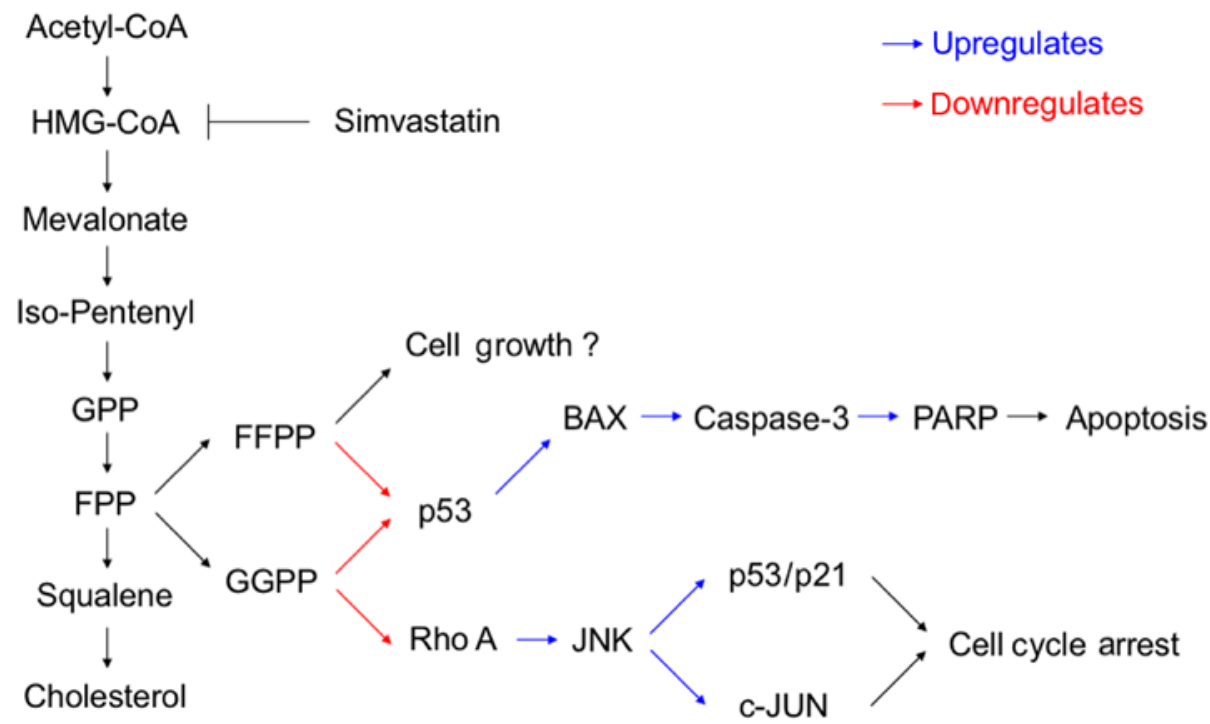

Figure 6. Schematic diagram of the mevalonate pathway and its proposed influence on the osteosarcoma cells in the present study. Simvastatin (HMG-CoA reductase inhibitors) inhibits the conversion of $\mathrm{HMG}-\mathrm{CoA}$ to mevalonate and thereby prevents the subsequent prenylation, and cholesterol formation. In parallel, by inhibiting geranylgeranylation or farnesylation, simvastatin reduces the activation of small G-proteins e.g. Rho A, which is associated with JNK activation and cell cycle arrest. Via inhibition of prenylation, p53 is induced by simvastatin with subsequent Bax induction and cleavage of caspase-3 and PARP resulting in apoptosis. Upregulation is indicated by blue arrows; downregulation is indicated by red arrows.

used $0.001-0.1 \mu \mathrm{M}$ to demonstrate the 'protective' properties, Fromigué et al used $10 \mu \mathrm{M}$. Sandoval-Usme et al reported that simvastatin inhibited the cell proliferation of osteosarcoma cells at a concentration higher than $10 \mu \mathrm{M}$ (28). Inhibition of osteosarcoma cell proliferation by simvastatin $(10 \mu \mathrm{M})$ was also shown by a Japanese group (29). Our findings demonstrated significantly inhibited osteosarcoma cell growth with 16 to $33 \mu \mathrm{M}$ simvastatin, emphasizing the need for higher concentrations for effective cancer treatment with simvastatin. However, increasing the dose of simvastatin raises a question about its clinical safety. Regarding the clinical application of simvastatin, this drug is administered for long-term conditions. The therapeutical range of simvastatin is at blood levels of simvastatin between 1 and $15 \mathrm{nmol} / \mathrm{l}(30)$. Yet, the potential side effects of simvastatin have been reported in large trials such as the Heart Protection Study (HPS) and Scandinavian Simvastatin Study (4S) $(31,32)$. HPS included over 20,500 patients who received a daily dose of $40 \mathrm{mg}$ simvastatin for a period of up to 5 years. Significant side-effects were myalgia ( $0.1 \%$ of patients) and elevation of transaminases $(n=21$ or $0.21 \%)$ and CK. The 4 S study with 4,444 patients and a 5-year follow-up is a famous study that shows the myalgiainducing effect of simvastatin. However, clinical trials to measure the maximum dose that is still tolerable in patients are sparse. A Dutch group treated 28 patients with myeloma or lymphoma with a 7-day period of escalating simvastatin dose. Tolerated doses were up to $15 \mathrm{mg} / \mathrm{kg}$ body weight/day and most reported side effects were fatigue and neutropenic fever (33). This indicates a potential role of a far higher simvastatin dose in oncologic patients than the statin therapy for cardiovascular disease, that is probably due to shorter application periods. The dose that was chosen in the present study was meant to clarify the molecular mechanism, and the possible use of simvastatin as an add-on drug to current chemotherapy. Additionally, we expect that a short-term exposure as a synergistic drug to chemotherapy will presumably have no significant side-effects.
Successful rescue from simvastatin's effects with FFP, GGPP and MA, implies the importance of the mevalonate pathway for malignant cells. Next to cell proliferation/growth, cancer cells elude the process of programmed cell death in order to grow exponentially beyond their physiological life span (34). In fact, the ability to evade apoptosis is a major criterion for cells to be considered malignant (35). Among other mechanisms, the release of proteins of the Bcl-2 family that mediate mitochondrial permeability can induce apoptosis (36). The balance between pro-apoptotic proteins (e.g. Bax, Bad and Bid) and anti-apoptotic proteins (Bcl-2, Bcl-W, Bfl-1) is the key to cytochrome $c$ release, which forms the apoptosome (with Apf-1 and caspase-9), that cleaves and thereby activates caspase-3 (36). Caspase-3 is the effective protease that cleaves DNA and e.g. PARP-1, hereby inactivating PARP-1 in its function to repair broken DNA strands, and stimulating further cell death $(37,38)$. Consequently, the reduction in Bcl-2 gene expression constitutes one target for activating apoptosis in cancer cells. Statin-induced apoptosis, which has been associated with Bcl-2 suppression, has been observed in breast cancer, human glioma, human cardiac myocytes and adenocarcinoma cells (39-41). A common feature in these studies is the concentrations $(1-20 \mu \mathrm{M})$ needed to cause apoptosis. While statin's effect on protein prenylation and mevalonate pathway is explained via HMG-CoA reductase inhibition, the exact mechanism underlying the suppression of $\mathrm{Bcl}-2$ remains unknown. The present study showed a significant increase in apoptotic cells after simvastatin therapy. This was reversed by adding GGPP but not FPP, which implies that GGPP-Ras and not FFP-Ras may dominantly activate certain pathways. In summary, simvastatin treatment shifted the Bax/Bcl-2 ratio at the mRNA level to a more pro-apoptotic ratio, an effect that was again reversible with downstream mediators of the mevalonate pathway. Considering that laryngeal cancer patients with increased Bax/Bcl-2 mRNA ratio have longer disease-free and overall survival (42), possibly, in osteosarcoma patients, 
this could lead to benefits as well. To verify our findings, we also investigated the protein expression of cleaved, and thus activated caspase-3 and cleaved, and thus inactivated PARP. As malignant cells are dependent on DNA damage repair by PARP as discussed above, an inhibition of the named protein constitutes a target for new therapies in breast cancer for example (43). Both cleaved proteins (caspase-3 and PARP) were upregulated by simvastatin therapy, and indicate their key role in the apoptosis of osteosarcoma cells. Comparable findings were reported by Woschek et al in regards to renal cancer cells by using 16 or $33 \mu \mathrm{M}$ simvastatin (19). Taken together, our study showed an induction of apoptosis mediators and subsequently apoptosis in malignant osteosarcoma cells by simvastatin in vitro.

Apart from eluding programmed cell death, deficient cell cycle regulation is another trait of cancer cells and their growth, which has been discussed above. The cell cycle is regulated by cyclin-dependent kinases (CDKs) and CDK inhibitors, that associate with cyclin proteins (44).

However, many cancer entities display mutations in cell cycle regulators, and thus exert an increased cell cycle rate (45). Therefore, the strategy of slowing down or arresting the cell cycle constitutes another important target for cancer therapies (45). Simvastatin was found to induce cell cycle arrest in pancreatic and endometrial cancer $(46,47)$. Similarly, simvastatin (16-64 $\mu \mathrm{M})$ induced cell cycle arrest via inhibition of CDKs in hepatic and renal cancer cells $(18,19)$. Yet, as the cell cycle is of upmost importance to cancer genesis it certainly has to be taken into account for the underlying mode-of-action of simvastatin in osteosarcoma cells, an approach that has not been addressed previously. In the present study, simvastatin treatment led to a significantly higher percentage of osteosarcoma cells in the G0/G1 phase, and therefore, in cell cycle arrest compared with the controls. Only GGPP and MA abolished these effects, findings that again indicate a mevalonate pathway dependency. However, data from the literature as well as our report suggest that further studies are needed to verify the proposed underlying mechanisms for simvastatin's mode-of-action. Furthermore, in previous studies with osteosarcoma samples obtained during surgery, alterations of TP53 were found in tumour tissue but not in normal tissue, thus indicating the importance of TP53 in tumour genesis (48). In more recent pathological studies of human tumour tissue, TP53 gene mutation was linked to susceptibility to osteosarcoma in childhood, resistance to chemotherapy as well as poor overall prognosis (49-51). In the present study, we found that simvastatin is a potent enhancer of TP53. Similar data were found for CDKN1A, which codes for p21 that in turn regulates cell cycle proteins including CDK1 and CDK2. After $48 \mathrm{~h}, \mathrm{CDKN} 1 \mathrm{~A}$ expression was significantly and dose-dependently reduced. Notably, CDC2 is responsible for cell cycle progression and thus a natural target for cell cycle arrest (52). Expression of $\mathrm{CDC} 2$ was markedly reduced under simvastatin therapy. In summary, malignant osteosarcoma cells treated with simvastatin are promoted to the G0/G1 phase with upregulation of TP53 and CDKN1A while CDC2 is downregulated. This is a novel finding for osteosarcoma cells, and may be a possible treatment target, which should be investigated in further in vivo studies.

One pathway more exclusively induced by GGPP-Ras is JNK (53). However, it has not been investigated for osteosarcoma in terms of statin treatment yet. Many effects of JNK are mediated by transcription factors of the activator protein-1 (AP-1) family, of which c-Jun is the most commonly known. Once these are activated, they form dimers and bind to enhancer or promoter regions of DNA. Research findings have indicated that AP-1 complexes do play a role in the expression of p53, and are able to enhance expression of p21 in osteosarcoma (54). Subsequently, c-Jun and JNK pathway not only mediate apoptosis but also the cell cycle arrest (55). The present study demonstrated a considerable increase in p-JNK and p-c-Jun expression, which are the phosphorylated and active forms of those proteins. However, there are groups, which have reported a downregulation of c-Jun after simvastatin therapy in U2OS cells (56). Certainly, JNK and c-Jun are activated by Rho kinases, so the question remains why these can be upregulated by simvastatin. A possible explanation for this phenomenon has been offered by others showing that statins may inhibit prenylation of Rho kinases, but some Rho proteins (RhoA, Rac1 and Cdc42) seem to be upregulated $(53,57,58)$. They may have reached their functionality without prenylation, and may subsequently activate JNK via Map kinases. This is supported by a recent study by Kamel et al, who demonstrated an impaired Rho efficacy and an enhanced MAPK pathway in an osteosarcoma simvastatin model (29).

Limitations of the study exist. We did not address an optional additive therapy option to cytostatic agents using simvastatin in combination with those. Optionally, a dosereduction of simvastatin may be reached by this approach. Further notably detailed mechanistical studies are required to evaluate the underlying pathways as well as the efficacy of the proposed treatment regime.

In conclusion, simvastatin has distinct effects on apoptosis and viability of osteosarcoma cells via JNK, and has to be considered and evaluated for the treatment of this disease in future studies.

\section{Acknowledgements}

We thank Katrin Jurida for outstanding technical assistance.

\section{Funding}

The present study was funded by institutional means.

\section{Availability of data and materials}

The datasets used and/or analyzed during the present study are available from the corresponding author on reasonable request.

\section{Authors' contributions}

BR designed the study, performed the statistical analyses and revised the manuscript. SK and MW carried out analyses and made the first draft of the manuscript. NK and RS carried out analyses. MK and MH contributed intellectually to the completion of the study.

\section{Ethics approval and consent to participate}

Not applicable. 


\section{Consent for publication}

Not applicable.

\section{Competing interests}

The authors declare that they have no competing interests.

\section{References}

1. Ottaviani G and Jaffe N: The etiology of osteosarcoma. Cancer Treat Res 152: 15-32, 2009.

2. Berner K, Hall KS, Monge OR, Weedon-Fekjær H, Zaikova O and Bruland OS: Prognostic factors and treatment results of highgrade osteosarcoma in norway: A scope beyond the 'classical' patient. Sarcoma 2015: 516843, 2015.

3. Li J, Yang Z, Li Y, Xia J, Li D, Li H, Ren M, Liao Y, Yu S, Chen Y, et al: Cell apoptosis, autophagy and necroptosis in osteosarcoma treatment. Oncotarget 7: 44763-44778, 2016.

4. Bielack SS, Kempf-Bielack B, Delling G, Exner GU, Flege S, Helmke K, Kotz R, Salzer-Kuntschik M, Werner M, Winkelmann W, et al: Prognostic factors in high-grade osteosarcoma of the extremities or trunk: An analysis of 1,702 patients treated on neoadjuvant cooperative osteosarcoma study group protocols. J Clin Oncol 20: 776-790, 2002.

5. Eftekhari F: Imaging assessment of osteosarcoma in childhood and adolescence: Diagnosis, staging, and evaluating response to chemotherapy. Cancer Treat Res 152: 33-62, 2009.

6. Salah S, Ahmad R, Sultan I, Yaser S and Shehadeh A: Osteosarcoma with metastasis at initial diagnosis: Current outcomes and prognostic factors in the context of a comprehensive cancer center. Mol Clin Oncol 2: 811-816, 2014

7. Luetke A, Meyers PA, Lewis I and Juergens H: Osteosarcoma treatment - where do we stand? A state of the art review. Cancer Treat Rev 40: 523-532, 2014.

8. Errani C, Longhi A, Rossi G, Rimondi E, Biazzo A, Toscano A Alì N, Ruggieri $\mathrm{P}$, Alberghini M, Picci $\mathrm{P}$, et al: Palliative therapy for osteosarcoma. Expert Rev Anticancer Ther 11: 217-227, 2011.

9. Schwarz R, Bruland O, Cassoni A, Schomberg P and Bielack S: The role of radiotherapy in oseosarcoma. Cancer Treat Res 152: 147-164, 2009.

10. Meyers PA, Schwartz CL, Krailo MD, Healey JH, Bernstein ML, Betcher D, Ferguson WS, Gebhardt MC, Goorin AM, Harris M, et al; Children's Oncology Group: Osteosarcoma: The addition of muramyl tripeptide to chemotherapy improves overall survival: A report from the Children's Oncology Group. J Clin Oncol 26 : 633-638, 2008.

11. Chou AJ, Kleinerman ES, Krailo MD, Chen Z, Betcher DL, Healey JH, Conrad EU III, Nieder ML, Weiner MA, Wells RJ, et al; Children's Oncology Group: Addition of muramyl tripeptide to chemotherapy for patients with newly diagnosed metastatic osteosarcoma: A report from the Children's Oncology Group. Cancer 115: 5339-5348, 2009.

12. Skinner R, Cotterill SJ and Stevens MC; United Kingdom Children's Cancer Study Group: Risk factors for nephrotoxicity after ifosfamide treatment in children: A UKCCSG Late Effects Group study. Br J Cancer 82: 1636-1645, 2000.

13. Arunkumar PA, Viswanatha GL, Radheshyam N, Mukund $H$ and Belliyappa MS: Science behind cisplatin-induced nephrotoxicity in humans: A clinical study. Asian Pac J Trop Biomed 2: 640-644, 2012

14. Davies JT, Delfino SF, Feinberg CE, Johnson MF, Nappi VL, Olinger JT, Schwab AP and Swanson HI: Current and emerging uses of statins in clinical therapeutics: A Review. Lipid Insights 9: 13-29, 2016.

15. Jeon CY, Pandol SJ, Wu B, Cook-Wiens G, Gottlieb RA, Merz CN and Goodman MT: The association of statin use after cancer diagnosis with survival in pancreatic cancer patients: A SEER-medicare analysis. PLoS One 10: e0121783, 2015.

16. Mei Z, Liang M, Li L, Zhang Y, Wang Q and Yang W: Effects of statins on cancer mortality and progression: A systematic review and meta-analysis of 95 cohorts including 1,111,407 individuals. Int J Cancer 140: 1068-1081, 2017.

17. Relja B, Meder F, Wang M, Blaheta R, Henrich D, Marzi I and Lehnert M: Simvastatin modulates the adhesion and growth of hepatocellular carcinoma cells via decrease of integrin expression and ROCK. Int J Oncol 38: 879-885, 2011
18. Relja B, Meder F, Wilhelm K, Henrich D, Marzi I and Lehnert M Simvastatin inhibits cell growth and induces apoptosis and G0/G1 cell cycle arrest in hepatic cancer cells. Int J Mol Med 26 735-741, 2010.

19. Woschek M, Kneip N, Jurida K, Marzi I and Relja B: Simvastatin reduces cancerogenic potential of renal cancer cells via heranylgeranyl pyrophosphate and mevalonate pathway. Nutr Cancer 68: 420-427, 2016.

20. Mullen PJ, Yu R, Longo J, Archer MC and Penn LZ: The interplay between cell signalling and the mevalonate pathway in cancer. Nat Rev Cancer 16: 718-731, 2016.

21. Zhou Q and Liao JK: Statins and cardiovascular diseases: From cholesterol lowering to pleiotropy. Curr Pharm Des 15: 467-478, 2009.

22. Klein MS, Koffarnus RL, Minze MG and Ochoa P: Achieving cholesterol goals with low-cost 3-hydroxy-3-methylglutaryl coenzyme-A (HMG Co-A) reductase inhibitors. Am J Health Syst Pharm 73 (Suppl 1): S63-S68, 2016.

23. Tricarico PM, Crovella S and Celsi F: Mevalonate pathway blockade, mitochondrial dysfunction and autophagy: A possible link. Int J Mol Sci 16: 16067-16084, 2015.

24. Garay T, Kenessey I, Molnár E, Juhász É, Réti A, László V, Rózsás A, Dobos J, Döme B, Berger W, et al: Prenylation inhibition-induced cell death in melanoma: Reduced sensitivity in BRAF mutant/PTEN wild-type melanoma cells. PLoS One 10: e0117021, 2015.

25. Wood CE, Hukkanen RR, Sura R, Jacobson-Kram D, Nolte T, Odin M and Cohen SM: Scientific and Regulatory Policy Committee (SRPC) Review: Interpretation and use of cell proliferation data in cancer risk assessment. Toxicol Pathol 43: 760-775, 2015.

26. Zhao XH, Xu ZR, Zhang Q and Yang YM: Simvastatin protects human osteosarcoma cells from oxidative stress-induced apoptosis through mitochondrial-mediated signaling. Mol Med Rep 5: 483-488, 2012.

27. Fromigué O, HaÿE, ModrowskiD, Bouvet S, Jacquel A, Auberger $P$ and Marie PJ: RhoA GTPase inactivation by statins induces osteosarcoma cell apoptosis by inhibiting p42/p44-MAPKs-Bcl-2 signaling independently of BMP-2 and cell differentiation. Cell Death Differ 13: 1845-1856, 2006.

28. Sandoval-Usme MC, Umaña-Pérez A, Guerra B, HernándezPerera O, García-Castellano JM, Fernández-Pérez L and Sánchez-Gómez M: Simvastatin impairs growth hormoneactivated signal transducer and activator of transcription (STAT) signaling pathway in UMR-106 osteosarcoma cells. PLoS One 9: e87769, 2014.

29. Kamel WA, Sugihara E, Nobusue H, Yamaguchi-Iwai S, Onishi N, Maki K, Fukuchi Y, Matsuo K, Muto A, Saya H, et al: Simvastatin-induced apoptosis in osteosarcoma cells: A Key role of RhoA-AMPK/p38 MAPK signaling in antitumor activity. Mol Cancer Ther 16: 182-192, 2017.

30. Björkhem-Bergman L, Lindh JD and Bergman P: What is a relevant statin concentration in cell experiments claiming pleiotropic effects? Br J Clin Pharmacol 72: 164-165, 2011.

31. No authors listed: Randomised trial of cholesterol lowering in 4444 patients with coronary heart disease: The Scandinavian Simvastatin Survival Study (4S). Lancet 344: 1383-1389, 1994.

32. Heart Protection Study Collaborative Group: MRC/BHF Heart Protection Study of cholesterol lowering with simvastatin in 20,536 high-risk individuals: A randomised placebo-controlled trial. Lancet 360: 7-22, 2002

33. van der Spek E, Bloem AC, van de Donk NW, Bogers LH van der Griend R, Kramer MH, de Weerdt O, Wittebol S and Lokhorst HM: Dose-finding study of high-dose simvastatin combined with standard chemotherapy in patients with relapsed or refractory myeloma or lymphoma. Haematologica 91: 542-545, 2006.

34. Fulda S: The mechanism of necroptosis in normal and cancer cells. Cancer Biol Ther 14: 999-1004, 2013.

35. Fulda S: Targeting apoptosis for anticancer therapy. Semin Cancer Biol 31: 84-88, 2015.

36. Jendrossek V: The intrinsic apoptosis pathways as a target in anticancer therapy. Curr Pharm Biotechnol 13: 1426-1438, 2012.

37. Andrabi SA, Kim NS, Yu SW, Wang H, Koh DW, Sasaki M, Klaus JA, Otsuka T, Zhang Z, Koehler RC, et al: Poly(ADP-ribose) (PAR) polymer is a death signal. Proc Natl Acad Sci USA 103: 18308-18313, 2006.

38. Kroemer G, Galluzzi L and Brenner C: Mitochondrial membrane permeabilization in cell death. Physiol Rev 87: 99-163, 2007. 
39. Spampanato C, De Maria S, Sarnataro M, Giordano E, Zanfardino M, Baiano S, Cartenì M and Morelli F: Simvastatin inhibits cancer cell growth by inducing apoptosis correlated to activation of Bax and downregulation of BCL-2 gene expression. Int J Oncol 40: 935-941, 2012.

40. Konturek PC, Burnat G and Hahn EG: Inhibition of Barret's adenocarcinoma cell growth by simvastatin: Involvement of COX-2 and apoptosis-related proteins. J Physiol Pharmacol 58 (Suppl 3): 141-148, 2007.

41. Lee HY, Kim IK, Lee HI, Mo JY, Yeo CD, Kang HH, Moon HS and Lee SH: The apoptotic effect of simvastatin via the upregulation of BIM in nonsmall cell lung cancer cells. Exp Lung Res 42: 14-23, 2016.

42. Giotakis AI, Kontos CK, Manolopoulos LD, Sismanis A, Konstadoulakis MM and Scorilas A: High BAX/BCL2 mRNA ratio predicts favorable prognosis in laryngeal squamous cell carcinoma, particularly in patients with negative lymph nodes at the time of diagnosis. Clin Biochem 49: 890-896, 2016.

43. O'Connor MJ: Targeting the DNA damage response in cancer. Mol Cell 60: 547-560, 2015.

44. Bendris N, Lemmers B and Blanchard JM: Cell cycle, cytoskeleton dynamics and beyond: The many functions of cyclins and CDK inhibitors. Cell Cycle 14: 1786-1798, 2015.

45. Dey N, Williams C, Leyland-Jones B and De P: Mutation matters in precision medicine: A future to believe in. Cancer Treat Rev 55 136-149, 2017.

46. Babcook MA, Sramkoski RM, Fujioka H, Daneshgari F, Almasan A, Shukla S, Nanavaty RR and Gupta S: Combination simvastatin and metformin induces G1-phase cell cycle arrest and Ripk1- and Ripk3-dependent necrosis in C4-2B osseous metastatic castration-resistant prostate cancer cells. Cell Death Dis 5: e1536, 2014.

47. Schointuch MN, Gilliam TP, Stine JE, Han X, Zhou C, Gehrig PA, Kim K and Bae-Jump VL: Simvastatin, an HMG-CoA reductase inhibitor, exhibits anti-metastatic and anti-tumorigenic effects in endometrial cancer. Gynecol Oncol 134: 346-355, 2014

48. Masuda H, Miller C, Koeffler HP, Battifora H and Cline MJ: Rearrangement of the $\mathrm{p} 53$ gene in human osteogenic sarcomas. Proc Natl Acad Sci USA 84: 7716-7719, 1987.
49. Mirabello L, Yeager M, Mai PL, Gastier-Foster JM, Gorlick R, Khanna C, Patiño-Garcia A, Sierrasesúmaga L, Lecanda F, Andrulis IL, et al: Germline TP53 variants and susceptibility to osteosarcoma. J Natl Cancer Inst 107: 107, 2015.

50. Goto A, Kanda H, Ishikawa Y, Matsumoto S, Kawaguchi N, Machinami R, Kato Y and Kitagawa T: Association of loss of heterozygosity at the p53 locus with chemoresistance in osteosarcomas. Jpn J Cancer Res 89: 539-547, 1998.

51. Chen Z, Guo J, Zhang K and Guo Y: TP53 mutations and survival in osteosarcoma patients: A meta-analysis of published data. Dis Markers 2016: 4639575, 2016.

52. Williams GH and Stoeber K: The cell cycle and cancer. J Pathol 226: 352-364, 2012.

53. Liang SL, Liu H and Zhou A: Lovastatin-induced apoptosis in macrophages through the $\mathrm{Rac} 1 / \mathrm{Cdc} 42 / \mathrm{JNK}$ pathway. J Immunol 177: 651-656, 2006.

54. Ogawa E, Okuyama R, Egawa T, Nagoshi H, Obinata M, Tagami H, Ikawa S and Aiba S: p63/p51-induced onset of keratinocyte differentiation via the c-Jun N-terminal kinase pathway is counteracted by keratinocyte growth factor. J Biol Chem 283: 34241-34249, 2008.

55. Dhanasekaran DN and Reddy EP: JNK signaling in apoptosis. Oncogene 27: 6245-6251, 2008.

56. Fromigué O, Hamidouche $\mathrm{Z}$ and Marie PJ: Blockade of the RhoA-JNK-c-Jun-MMP2 cascade by atorvastatin reduces osteosarcoma cell invasion. J Biol Chem 283: 30549-30556, 2008.

57. Zhu Y, Casey PJ, Kumar AP and Pervaiz S: Deciphering the signaling networks underlying simvastatin-induced apoptosis in human cancer cells: Evidence for non-canonical activation of RhoA and Racl GTPases. Cell Death Dis 4: e568, 2013.

58. Sassano A, Katsoulidis E, Antico G, Altman JK, Redig AJ, Minucci S, Tallman MS and Platanias LC: Suppressive effects of statins on acute promyelocytic leukemia cells. Cancer Res 67: 4524-4532, 2007. 